\title{
Correction to: Processing and Analyzing Human Microbiome Data
}

\section{Xuan Zhu, Jian Wang, Cielito Reyes-Gibby, and Sanjay Shete}

Correction to:

Chapter 31 in: Robert C. Elston (ed.),

Statistical Human Genetics: Methods and Protocols, Methods in Molecular Biology, vol. 1666, https://doi.org/10.1007/978-1-4939-7274-6_31

The original version of this chapter was inadvertently published without including the $\mathrm{dbGaP}$ acknowledgment. The updated chapter now contains that information.

The updated online version of this chapter can be found at https://doi.org/10.1007/978-1-4939-7274-6_31 